\title{
Pengaruh Model Learning Cycle 7E dan Kecerdasan Interpersonal Terhadap Pemahaman Konsep IPA
}

\author{
Saiful Bahri ${ }^{1 *}$, Adi Apriadi Adiansha ${ }^{2}$ \\ ${ }^{1}$ Universitas Sains Cut Nyak Dien, Langsa, Aceh \\ ${ }^{2}$ STKIP Taman Siswa Bima, Bima, NTB \\ "email: saifulbahriunj@gmail.com
}

Abstract. The Effect of $7 E$ Learning Cycle Model and Interpersonal Intelligence on the Understanding of Science Concept. The purpose of this study was to determine the effect of the $7 E$ Cycle Study Model and Interpersonal Intelligence on the understanding students' science concepts. This research was conducted at SDN Pelita Harapan Jaya 01 . The research design used was treatment by level $2 \times 2$, with the independent variable being the learning cycle model $7 e$ and conventional, the dependent variable was the understanding of the concept of science, and the moderator variable was interpersonal intelligence. The sampling technique used was cluster random sampling. The results of this study showed the learning cycle $7 e$ model can improve students understanding of the science concept, so that this strategy can be used by elementary school teachers in energy source material. More over this model affects students understanding of science concepts depending on the level of students interpersonal intelligence. In addition students who have a high level of interpersonal intelligence have a higher science concept score compared to conventional learning.

Keywords: learning cycle 7E, understanding the concept of science, interpersonal intelligence

\begin{abstract}
Pengaruh Model Learning Cycle 7E dan Kecerdasan Interpersonal Terhadap Pemahaman Konsep IPA. Tujuan penelitian ini adalah mengetahui pengaruh Model Learnig Cycle $7 E$ dan Kecerdasan Interpersonal terhadap Pemahaman konsep IPA siswa. Penelitian ini dilakukan di SDN Pelita Harapan Jaya 01. Desain penelitian yang digunakan adalah treatment by level $2 \times 2$, dengan variabel bebas adalah model learning cycle $7 e$ dan konvensional, variabel terikat adalah pemahaman konsep IPA, dan variabel moderator adalah kecerdasan interpersonal. Teknik pengambilan sampel yang digunakan cluster random sampling. Hasil penelitian ini adalah pertama model learning cycle $7 e$ efektif untuk meningkatkan pemahaman konsep IPA sehingga strategi ini dapat digunakan guru sekolah dasar dalam materi sumber energi. Kedua, pembelajaran berpengaruh terhadap pemahaman konsep IPA siswa tergantung dengan tingkat kecerdasan interpersonal siswa. Ketiga, dengan model learning cycle 7e siswa yang memiliki tingkat kecerdasan interpersonal tinggi memiliki skor pemahaman konsep IPA yang lebih tinggi dibandingkan dengan pembelajaran konvensional.
\end{abstract}

Kata Kunci : learning cycle 7E, pemahaman konsep IPA, kecerdasan interpersonal 


\section{PENDAHULUAN}

Pendidikan Ilmu Pengetahuan Alam (IPA) merupakan sesuatu hal yang sangat penting dalam proses pembelajaran, dalam proses pembelajaran IPA sangat menekankan pada pemberian pengalaman langsung untuk mengembangkan kompetensi peserta didik agar mampu menjelajahi dan memahami alam sekitar secara ilmiah. Oleh karena itu, pembelajaran yang diterapkan dalam menyajikan pembelajaran IPA adalah memadukan antara pengalaman proses IPA dan pemahaman konsep IPA dalam bentuk pengalaman langsung.

$$
\text { Hasil Programme for }
$$

International Student Assessment (PISA) tahun 2015 yang diikuti oleh 70 Negara menunjukkan bahwa Indonesia menduduki peringkat ke 62 dengan nilai rata-rata 403 di bawah standar ketentuan dari PISA yaitu 500. Hal tersebut menunjukkan bahwa pemahaman IPA di Indonesia sangat lemah, sehingga diperlukan model pembelajaran yang dapat meningkatkan pemahaman konsep dalam pembelajaran IPA. Hal tersebut merupakan masalah yang sangat serius dalam meningkatkan kemampuan pembelajaran IPA, untuk mengatasi masalah tersebut diperlukan model pembelajaran yang mampu meningkatkan pemahaman konsep IPA yakni model Cycle Elicit, Engage, Exploration, Explaination, Elaboration, Evaluation and Extend (Cycle 7E). Model pembelajaran tersebut sangat cocok digunakan dalam mewadahi atau mengakomodir permasalah tersebut. Eisenkraft mengemukakan tujuan pembelajaran Cycle $7 E$ adalah sebagai berikut:

The goal of the $7 E$ learning model is to emphasize the increasing importance of eliciting prior understandings and the extending, or transfer, of concepts. With this new model, teachers should no longer overlook these essential requirements for student learning.

Dijelaskan bahwa dalam tujuan pembelajaran Cycle $7 E$ merupakan untuk menekankan pentingnya peningkatan Cycle $7 E$ sebelumnya pemahaman dan memperluas, atau transfer, konsep. Dengan model baru ini, guru tidak boleh mengabaikan persyaratan ini penting untuk belajar siswa.

\section{Pemahaman Konsep IPA}

Konsep merupakan kesimpulan dari suatu pengertian yang terdiri dari dua atau lebih fakta dengan memiliki ciri-ciri yang sama, untuk menanamkan suatu konsep dalam pelajaran, seorang guru perlu mengajarkannya dalam konteks nyata dengan mengaitkannya terhadap lingkungan sekitar. Hal ini akan mampu mengembangkan kemampuan berpikir kritis siswa dan meningkatkan pemahaman konsepnya terhadap materi yang diajarkan.

Terdapat proses perubahan konsep yang mirip dengan yang ada dalam filsafat IPA. Tahap pertama dalam perubahan konsep adalah asimilasi, tahap berikutnya adalah akomodasi. Pada tahap asilimasi, seorang peserta didik menggunakan konsep-konsep yang dimiliki untuk dapat mempelajari fenomena baru. Pada tahap akomodasi, seorang peserta didik akan melakukan penyesuain konsep yang dimiliki dengan konsep yang sedang dipelajari, hal ini disebabkan konsep yang dimiliki peserta didik berbeda dengan konsep yang sedang dipelajarinya. Agar terjadi proses akomodasi dibutuhkan beberapa keadaan dan syarat sebagai berikut.

a. Harus ada ketidakpuasan terhadap konsep yang telah ada. Peserta didik harus yakin bahwa konsep lama mereka sudah tidak dapat lagi 
digunakan untuk mempelajari fenomena baru.

b. Konsep yang baru harus dapat dimengerti, rasional, dan memecahkan masalah atau fenomena baru.

c. Konsep yang baru harus masuk akal, dapat memecahkan dan menjawab persoalan yang terdahulu, dan konsisten dengan teori yang telah disusun.

Dengan demikian dapat diartiakan bahwa pemahaman konsep adalah suatu pemahaman siswa pada materi yang akan diajarkan secara lebih rinci dengan menggunakan kata-kata sendiri.

\section{Model Learning Cycle 7E}

Learning Cycle merupakan salah satu model pembelajaran yang berlandaskan pada pandangan konstruktif. Pandangan ini berasumsi bahwa mengajar bukan sebagai proses di mana gagasan-gagasan guru (dosen) diteruskan pada para peserta didik, melainkan sebagai proses untuk mengubah dan membangun gagasangagasan peserta didik yang sudah ada. Seperti yang diungkapkan oleh Renner, dkk (1988) Model Learning Cycle menekankan pada model pembelajaran yang berorientasi kehakikat sains yaitu sebagai produk, proses dan alat untuk mengembangkan sikap ilmiah.

Peserta didik dapat terlibat langsung dalam proses pembelajaran sehingga diharapkan dapat meningkatkan hasil belajar peserta didik. Model pembelajaran siklus adalah suatu kerangka konseptual yang digunakan sebagai pedoman dalam melakukan proses pembelajaran yang berpusat pada siswa. Siklus belajar (Learning Cycle 7E) merupakan salah satu model pembelajaran dengan pendekatan konstruktivis yang pada mulanya terdiri atas tiga tahap, yaitu
Eksplorasi (exploration), Pengenalan konsep (concept introduction), dan Penerapan konsep (concept application). Pada proses selanjutnya, Tiga siklus tersebut saat ini dikembangkan menjadi lima tahap yang sering disebut dengan Learning Cycle 5E. Tahapan dari Learning Cycle 5E yaitu engage, explore, explain, extend dan evaluate. Pada proses selanjutya Eisenkraft (2003) mengembangkan siklus belajar menjadi tujuh tahap. Tujuh tahap dari model Learning Cycle $7 E$ adalah menekankan pada pentingnya memperoleh pemahaman konsep sebelumnya atau transfer konsep.

Model pembelajaran learning cycle $7 E$ merupakan salah satu model pembelajaran yang memberikan kesempatan kepada siswa untuk mengoptimalkan cara belajar dan mengembangkan daya nalar siswa. Dalam model pembelajaran learning cycle $7 E$ memiliki kelebihan antara lain merangsang siswa untuk mengingat kembali materi pelajaran yang telah mereka dapatkan sebelumnya: memberikan motivasi kepada siswa untuk menjadi lebih aktif dan menambah rasa ingin tahu siswa; melatih siswa belajar menemukan konsep melalui eksperimen; melatih siswa untuk menyampaikan secara lisan konsep yang telah mereka pelajari; memberikan kesempatan kepada siswa untuk berpikir, mencari, menemukan dan menjelaskan contoh penerapan konsep yang telah dipelajari.; guru dan siswa menjalankan tahapan-tahapan pembelajaran yang saling mengisi satu sama lainnya.

Kelebihan model pembelajaran learning cycle yaitu: meningkatkan motivasi belajar karena peserta didik dilibatkan secara aktif dalam proses pembelajaran, membantu mengembangkan sikap ilmiah peserta didik, pembelajaran menjadi lebih 
bermakna. Sedangkan kelemahan model pembelajaran learning cycle yaitu: efektifitas pembelajaran rendah jika guru kurang menguasai materi dan langkah-langkah pembelajaran, menuntut kesungguhan dan kreatifitas guru dalam merancang dan melaksanakan proses pembelajaran, memerlukan pengelolaan kelas yang lebih terencana dan terorganisasi, memerlukan waktu dan tenaga yang lebih banyak dalam menyusun rencana dan melaksanakan pembelajaran.

Sehingga dari penjelasan tersebut, model pembelajaran learning cycle $\quad 7 E$ merupakan model pembelajaran student centered dengan mengadopsi prinsip konstruktivisme yang terdiri rangkaian tahap-tahap kegiatan (fase) yaitu tahap elicit, engage, explore, explain, elaborate, evaluate, dan extend, yang diorganisasi sedemikian rupa sehingga peserta didik dapat menguasai kompetensi yang harus dicapai dalam pembelajaran dengan jalan berperan aktif. Sehingga dari penjelasan tersebut, model pembelajaran learning cycle $7 E$ merupakan model pembelajaran student centered dengan mengadopsi prinsip konstruktivisme yang diorganisasi sedemikian rupa sehingga peserta didik dapat menguasai kompetensi yang harus dicapai dalam pembelajaran dengan jalan berperan aktif

\section{Kecerdasan Interpersonal}

Gardner dalam Armstrong
mengatakan bahwa kecerdasan
interpersonal adalah kemampuan untuk
memahami dan membuat perbedaan-
perbedaan pada suasana hati, maksud,
motivasi, dan perasaan terhadap orang
lain. Hal ini mencakup kepekaan
terhadap ekspresi wajah, suara, dan
gerak tubuh dan kemampuan merespons
isyarat-isyarat tersebut dalam beberapa

pragmatis untuk mempengaruhi sekelompok orang agar mengikuti jalur tertentu dari suatu tindakan.

Gardner dalam suyono mengungkapkan bahwa kecerdasan interpersonal adalah seseorang yang memiliki potensi kecerdasan ini mudah berkomunikasi yang baik dengan orang lain, cocok bagi profesi hubungan masyarakat, diplomat, duta besar, menteri luar negeri,dan yang keberhasilanya amat bergantung pada kecakapan komunikasi antar manusia.

Adapun faktor yang mempengaruhi kecerdasan interpersonal yang dikemukan boeree adalah sebagai berikut:

1) Lingkungan keluarga, dimana anak memerlukan perawatan serta perhatian orang tua.

2) Nutrisi, dimana pengaruh kekurangan nutrisi tidak terjadi secara langsung. Anak yang mengalami kekurangan gizi biasanya kurang responsif pada saat dewasa, kurang termotivasi untuk belajar, dan kurang aktif dalam mengeksplorasi daripada anak-anak yang cukup mendapatkan nutrisi.

Pengalaman hidup individu. Anak tumbuh dan berkembang di lingkungan keluarga, hubungan sosial pertama kali diperoleh individu melalui orang tua. Faktor yang mempengaruhi perkembangan dan pertumbuhan anak adalah pola asuh. Pola asuh orang tua yang permisif, otoriter, demokratis sangat mempengaruhi tumbuh kembang anak. Oleh karena itu setiap gaya pengasuhan anak oleh orang tua akan berdampak berbeda pada setiap individu

\section{METODE}

Penelitian ini merupakan penelitian eksperimen dengan variabel terikat adalah pemahaman konsep IPA siswa dan variabel bebas terdiri dari 
variabel perlakuan dan variabel moderator. Variabel perlakuan adalah model learning cycle $7 e$ (A1) dan pembelajaran konvensional (A2). Variabel moderator adalah kecerdasan interpersonal siswa yang terdiri dari kecerdasan interpersonal tinggi (B1) dan kecerdasan interpersonal rendah (B2). Penelitian ini dirancang percobaannya dengan menggunakan desain treatment by level $2 \times 2$, seperti pada Tabel 1 berikut:

Tabel 1. Desain Eksperimen

\begin{tabular}{ccc}
\hline & \multicolumn{2}{c}{ Variabel Perlakuan (A) } \\
\cline { 2 - 3 } $\begin{array}{c}\text { Variabel Atribut } \\
\text { Kecerdasan } \\
\text { Interpersonal(B) }\end{array}$ & $\begin{array}{c}\text { Mearning } \\
\text { Cycle } 7 E \\
\text { (A1) }\end{array}$ & $\begin{array}{c}\text { Pemb. } \\
\text { Konvensional } \\
\text { (A2) }\end{array}$ \\
$\begin{array}{c}\text { Kecerdasan } \\
\text { Interpersonal } \\
\text { Tinggi (B1) } \\
\begin{array}{c}\text { Berpikir Kreatif } \\
\text { Rendah (B2) }\end{array}\end{array}$ & A1B1 & A2B1 \\
\hline
\end{tabular}

A1B1 = Skor Pemahaman konsep IPA pada Kelompok siswa (Kelas Eksperimen) yang memperoleh model learning cycle $7 e$ dengan kecerdasan interpersonal tinggi

A1B2 = Skor Pemahaman konsep IPA pada Kelompok siswa (Kelas Eksperimen) yang memperoleh model learning cycle $7 e$ dengan kecerdasan interpersonal rendah

A2B1 = Skor Pemahaman konsep IPA pada Kelompok siswa (Kelas Kontrol) yang memperoleh pembelajaran Konvensional dengan kecerdasan interpersonal tinggi

A2B2 = Skor Pemahaman konsep IPA pada Kelompok siswa (Kelas Kontrol) yang memperoleh pembelajaran Konvensional dengan kecerdasan interpersonal rendah
Populasi dalam penelitian ini adalah populasi target seluruh siswa kelas III di SDN Pelita Harapan Jaya 01 tahun pelajaran 2018/2019. Populasi terjang kaunya siswa kelas III sebanyak 4 Kelas mata pelajaran IPA dengan materi sumber energi. Teknik pengambilam sampel dilakukan dengan Cluster Random Sampling. siswa yang mengikuti mata pelajaran ini ada kelas 2 kelas. Dari 4 kelas diambil 2 kelas secara acak yaitu kelas III-A dan kelas III-B dimana untuk kelas III-A terdiri dari 30 siswa dan kelas III-B terdiri dari 30 siswa. Dari kedua kelas ditentukan secara acak untuk dijadikan kelas eksperimen dan kelas kontrol, yaitu kelas III-A sebagai kelas eksperimen yang mendapat Model learning cycle 7e dan kelas III-B sebagai kelas kontrol dengan pembelajaran Konvensional. Kemudian setelah melakukan tes kecerdasan interpersonal, penentuan kelompok kecerdasan interpersonal tinggi dan kecerdasan interpersonal rendah dilakukan dengan menyusun urutan responden berdasarkan skor kecerdasan interpersonal yang diperoleh, yaitu skor tertinggi hingga skor terendah. Untuk mendapatkan kelompok tinggi dan kelompok rendah S. Naga (2012) mengemukakan, ukuran untuk menentukan kelompok tinggi dan kelompok rendah adalah $27 \%$. Jadi, sampel penelitian ini terdiri dari dua kelas, yang masing-masing kelas dibagi menjadi dua kelompok, dengan menggambil $27 \%$ siswa kecerdasan interpersonal tinggi dan siswa kecerdasan interpersonal rendah.

Instrumen pemahaman konsep IPA berbentuk tes pilihan ganda. Instrumen terdiri mengukur materi sumber energi. Respon peserta divaliditas isi 1 orang pakar pendidikan IPA untuk melihat kesesuaian butir dengan indikator, kebenaran materi, 
kontruksi dan bahasa. Untuk menghitung validitas butir tes yang dilakukan menggunakan product moment. Hasil pengujian validasi isi menunjukkan bahwa 20 butir soal pemahaman konsep IPA $r_{\text {hitung }}>$ $r_{\text {tabel }}$ yaitu valid. Sedangkan instrumen kecerdasan interpersonal berbentuk tes angket sebanyak 10 butir soal dan 10 butir yang valid.

\section{HASIL DAN PEMBAHASAN}

Setelah melakukan penelitian, data hasil penelitian di analisis dan menunjukkan bahwa skor rata-rata pemahaman konsep IPA siswa yang menggunakan strategi model learning cycle 7e sebesar 100 lebih tinggi dibanding yang menggunakan pembelajaran konvensional sebesar 85 . Sedangkan untuk skor rata-rata kecerdasan interpersonal siswa pada kelompok A1B1, A1B2, A2B1 dan A2B2 berturut-turut 93,$75 ; 80,62$; 78,$12 ; 66,25$.

Dari hasil penelitian ini menunjukkan selisih rentang skor ratarata pemahaman konsep IPA siswa menunjukkan bahwa terdapat perbedaan pemahaman konsep IPA siswa pada kedua kelas. Pernyataan ini di dukung dengan hasil pengujian dengan menggunakan anova dua jalur, membandingkan skor pemahaman konsep IPA siswa pada kelompok A1 dan A2 diperoleh sig. $=37,86<4,20=\alpha$ dan skor pada kelompok A1 lebih tinggi dari kelompok A2. Ini berarti skor pemahaman konsep IPA kelompok siswa yang menggunakan model learning cycle $7 e$ (A1) lebih tinggi dari skor kemampuan komunikasi matematis siswa yang menggunakan pembelajaran ekspositori (A2) menjadi temuan pertama dalam penelitian ini. Ini menunjukkan bahwa pemberian model learning cycle $7 e$ lebih efektif meningkatkan pemahaman konsep IPA siswa.

Hasil pengujian interaksi antara strategi pembelajaran dan kecerdasan interpersonal $(\mathrm{A} * \mathrm{~B}) \quad$ diperoleh sign. $=6,57<\alpha=4,20$, ini berarti terdapat interaksi startegi pembelajaran dan kecerdasan interpersonall terhadap skor pemahaman konsep IPA. Jadi temuan kedua dalam penelitian yaitu bahwa adanya interaksi membuktikan bahwa masing-masing pembelajaran memberi pengaruh yang berbeda terhadap pemahaman konsep IPA siswa jika diterapkan pada kelompok siswa yang memiliki tingkat kecerdasan interpersonal yang berbeda pula.

Pengujian hipotesis selanjutnya menggunakan uji Tukay. Karena nilai homogenitis menunjukkan sig. > 0,05 pada semua variabel. Hasil pengujian menunjukkan untuk kelompok A1B1 dan $\mathrm{A} 2 \mathrm{~B} 1$ nilai sig. $=6,97>02,74=\alpha$ dan skor A1B1 lebih tinggi dari A2B1. Artinya skor pemahaman konsep IPA siswa dengan tingkat kecerdasan interpersonal tinggi yang menggunakan model learning cycle $7 e$ lebih tinggi dibandingkan pembelajaran ekspositori. Namun, hasil berbeda untuk kelompok A1B2dan A2B2 nilai sig. $=2,87>2,74$, tidak terdapat perbedaan yang signifikan antara skor pemahaman konsep IPA siswa dengan tingkat kecerdasan interpersonal rendah yang menggunakan model learning cycle $7 e$ lebih tinggi dibandingkan pembelajaran konvensional.

Telah diuraikan diatas, bahwa penggunaan model learning cycle $7 e$ mampu mengembangkan pemahaman konsep IPA siswa, karena mampu memberikan kesempatan kepada siswa untuk berinteraksi dalam menyampaikan ide-idenya, merefleksikan gagasan yang diberikan temannya dan berdiskusi dalam menyamakan yang memanfaatkan $7 \mathrm{E}$ 
(Elicit, Engage, Exploration, Explaination, Elaboration, Evaluation and Extend,Cycle 7E) proses yang terjadi dalam kegiatan belajar maka pembelajaran sangat efektif dan mudah diikuti.

Kecerdasan Interpersonal adalah kemampuan untuk memahami dan membuat perbedaan-perbedaan pada suasana hati, maksud, motivasi, dan perasaan terhadap orang lain. Kecrdasan Interpersonal dapat menjadi bekal untuk siswa dalam memberikan ide kreatif dalam pemikirannya. siswa dengan tingkat kecerdasan interpersonal tinggi belajar dengan model learning cycle $7 e$ akan meningkatkan pemahaman konsep IPA.

\section{SIMPULAN}

Dari penelitian ini di harapkan guru dalam memberikan pelayanan pendidikan kepada siswanya, tidak hanya memperhatikan hasil belajar, namun juga memperhatikan kemampuan matematis yang lebih tinggi. guru juga diharapkan dapat menerapkan strategi pembelajaran REACT dalam proses kegiatan belajar mengajar, untuk kemampuan komunikasi matematis siswanya, yang nantinya akan berdampak pula pada peningkatan prestasi belajar siswanya.

\section{REFERENSI}

Armstrong. (2013). Kecerdasan Multipel di Dalam Kelas. Jakarta: PT Indeks

Arthur Eisenkraft. (2003) Expanding the 5E Model A proposed $7 E$ model emphasizes "transfer of learning" and the importance of eliciting prior understanding. Published by the National Science Teachers Association.

Eka Sulistyowati. (2014). Metodologi Pembelajaran IPA. (Jakarta: Bumi Aksara, h.41-43
Kemendikbud. (2013) Peraturan Menteri Pendidikan Pendidikan Dan Kebudayaan Republik Indonesia Nomor 70 Tahun 2013. Jakarta: Kementrian Pendidikan dan Kebudayaan.

Ngalimun. (2014). Strategi dan Model Pembelajaran. Yogyakarta: Aswaja Pressinso.

Ni Putu Widiawati, Ketut Pudjawan, I Gd Margunayasa. (2015).

Analisis Pemahaman Konsep Dalam Pelajaran IPA Pada Siswa Kelas IV Sd Di Gugus II Kecamatan Banjar. PGSD Universitas Pendidikan Ganesha. 3(1).

Monawati. (2015). Hubungan antara Kecerdasan interpersonal dengan Prestasi Belajar. Jurnal pesona Dasar PGSD Universitas Syiah Kuala. 3(3):26

OECD. (2016). PISA 2015 Results: What Students Know and Can Do-Student Performance in Mathematics, Reading and Science. $\quad$ PISA: OECD Publishing.

Sugiyono. (2015). Statistika Untuk Penelitian. Bandung : Alfabeta.

Suyuno. (2015). Implementasi Belajar dan Pembelajaran. Bandung: PT Remaja Rosdakarya.

Syafrudin, U., Edwita, E., \& Sarkadi, S. (2018). Pembelajaran Unik Pada Anak Yang Memiliki Kecerdasan Visual Spasial Yang Mengalami Kesulitan Belajar. Elementary: Jurnal Ilmiah Pendidikan Dasar, 4(2), 149-160. doi:10.32332/elementary.v4i2.1 231

Theresia K.Brahim, Kusmajid Abdullah \& Najib Hasan. (2015). Penelitian Ilmiah (Pengertian, Penerapan, dan Pengetahuan 
Jurnal Pendidikan Anak, April 2020, p :44-51

E-ISSN: 2580-9504
Vol. 6, No. 1

DOI:

Tambahan). Jakarta: Suara

GKYE Peduli Bangsa. 